\author{
J ournal of Nobel Medical College \\ A vailable Online: www.nepjol.info, www.nobelmedicalcollege.com.np \\ Volume 5, Number 2, Issue 9 (Aug.-Dec., 2016), i-ii
}

$\underline{\text { Editorial }}$

\title{
Molecular Aspects of Human Body's Intelligently Designed Complex Living System
}

\author{
A rambam Giridhari Singh \\ Department of Biochemistry, Nobel Medical College Teaching Hospital, Biratnagar, Nepal
}

There are certain aspects of natural world so intricate and fit for purpose that they can't be taken as evolved but must have been created by an intelligent designer. The term intelligent design (ID) has now been accepted as a theory for deciding that a living body can't have arisen by chance but designed and created by some antity. To know whether a system of a living body is of intelligent design or not, evidences related to the concerned system are to be collected and see if they can really be evidences of a planned, genuine design or can lead to a conclusion that blind, random chances be remained as the organizing principle of life. [ intelligent design. org].

Human body is comprised of an amalgamation of different systems together making a complex organism that exhibit symmetry and order. Some of these systems have now been established as showing evidence of intelligent design thereby opposing the earlier evolution theory of life proposed by Charles Darwin.

Theist scholar Dr Brad Harrub [1] discussed the complex function of human brain and its relationship with the nervous system in his article: "The Human nervous system: Evidence of intelligent design [part I]". After thorough discussion on the mechanism of action of neurotransmitters, their synthesis, storage etc, it was found to be too complex to have happened by mere accidents. He considered this system as evidence of intelligent design. Dr Brad's next target was on the Human circulatory system. After discussion on how the heart and vessels came to so well laid out within the body, protection of the heart by a bony cage, it's management for a continuous beating etc, a conclusion was brought for considering this system also as evidence of intelligent design.

Another amazing function of Human is the act of conception. Professor Keith Moore [2] examined the complexities of conception in great detail on how the chromosomes from both the ovum and the cell fuse together to form a brand-new cell then divide and grow. The symmetry of Human body from conception to birth is overwhelming and it seems illogical to assert that random occurrence is responsible. Many more works on human systems are in the pipe line for exposure. Thus, in due course of time, every system in our body may be listed as evidences of intelligent design supporting the theory of creation.

A finely regulated molecular transformation in our body as evidence of intelligent design (a topic open for comments). Everyone of us living on this earth do admit that the greatest of all the creations is man himself and we all have come to know that the activity and status of a living body is depicted by finely regulated system of molecular transformation. J oseph Paturi [3] in his article: "The human body- God's masterpiece" suggested of having a chemical plant far more intricate than any plant man has ever built. This plant changes the food we eat into living tissues, causes the growth of flesh, blood, bones and teeth. It 
repairs the body when parts are damaged by accident or disease. Power for work and play also derived from the food we eat.

Selecting bimolecular transformation as a device for maintaining a life activity is itself an intelligent decision; because, every step of the transformation can be traced and identified creating rooms for correction if alteration arises. (Medical Science).

Out of the many systems operating in our body if we pick up the GI system as the beginning, we will find it's molecular status (in the process of digestion and absorption) as mostly of transformation of macromolecular structure like proteins, fats, polysaccharides, nuceic acid etc to the smallest possible molecular structures like amino acids, fatty acids, glucose, purines, pyrimidines etc using a set of enzymes already kept ready for secretions at the allocated locations such as salivary gland, stomach, pancreas and succus entericus. The secretion of these enzymes will again be regulated by a set of biomolecules known as secretagogues like acetyl choline, catacholimines, histamine, gastrin, cholecystikinin, secretin, serotonin etc.

Some of the additional arrangements we see in the GI system during this biotransformation process for safe and smooth utilization of the ingested food are as listed below. 1. Production and storage of $\mathrm{HCL}$ for the denaturation of proteins ingested for easier digestion, killing of microorganism if any and activation of pepsinogen to pepsin.2. secretion of proteolytic enzymes in it's zymogen form (inactive) just to protect the GI lining from the possible attack of those enzymes when active. 3. Production of bile acids and salts to facilitate the digestion and absorption of lipids. All these arrangements can be made possible by formation of all these required molecules in the body itself by enzymatic reaction only. All the required enzymes are to be synthesized through series of molecular transformation starting from DNA, the wonder molecule.

DNA in living creatures shows strong evidence of the creator. It carries information that can't have occurred by natural forces but came from an intelligent being.

Dear colleagues, these points related to GI system mentioned above, can be taken as evidences we have collected from this small area of Human system. Kindly, go a little deeper to get more evidences if you want and bring it to a conclusion with your own justification that, this much complexity we are finding in this system can be of a natural selection or, would you like to categories it as of intelligent design??

Let us try to know the complexity of all the systems in our body to get more evidences for discussion on this line.

References

[1] Harrub B, The Human Nervous System: Evidence of Intelligent Design, Reason \& Revelation, Apologetics press.

[2] Moore KL, The developing human: Clinically oriented embryology, English, Book. 34 (2013)

[3] Paturi J, The human body-God's masterpiece, creation. 20:4 (1998) 54-57. 